\title{
Article \\ Training and Detraining Effects of a Rehabilitation Program with or without Electro-Cryotherapy in Patients with Anterior Knee Pain: A Randomized Trial
}

\author{
Yuyeon Roh $^{1}$ and Jihong Park ${ }^{2, *(D)}$ \\ 1 Athletic Training Laboratory, Department of Physical education, Graduate School, Kyung Hee University, \\ Yongin 17104, Korea; shdbdus321@khu.ac.kr \\ 2 Athletic Training Laboratory, Department of Sports Medicine, Kyung Hee University, Yongin 17104, Korea \\ * Correspondence: jihong.park@khu.ac.kr; Tel.: +82-31-201-2721
}

Citation: Roh, Y.; Park, J. Training and Detraining Effects of a

Rehabilitation Program with or without Electro-Cryotherapy in Patients with Anterior Knee Pain: A Randomized Trial. Appl. Sci. 2021, 11, 4812. https://doi.org/10.3390/ app11114812

Academic Editor: Hanatsu Nagano

Received: 1 April 2021

Accepted: 21 May 2021

Published: 24 May 2021

Publisher's Note: MDPI stays neutral with regard to jurisdictional claims in published maps and institutional affiliations.

Copyright: (c) 2021 by the authors. Licensee MDPI, Basel, Switzerland. This article is an open access article distributed under the terms and conditions of the Creative Commons Attribution (CC BY) license (https:// creativecommons.org/licenses/by/ $4.0 /)$.

\begin{abstract}
We investigated the effect of ten-sessions (with or without receiving modalities) of training and 4-weeks of detraining in individuals with anterior knee pain (AKP). Thirty patients with AKP (19 males; 11 females; pain duration: 46 months) were randomly assigned to either a rehabilitation program (with or without pre-exercise modality). Quadriceps (strength, activation, power, and endurance) and self-reported functions (pain perception and functional outcomes) were recorded pre- and post-rehabilitation and detraining (4-weeks). The application of electro-cryotherapy did not produce a summative effect on quadriceps or self-reported functions (condition $\times$ time: $F_{2,56}<2.27$, $p>0.11$ for all tests). Regardless of the modality application (time effect), quadriceps (strength: $12 \%$, $p=0.06$; power: $20 \%, p=0.006$; endurance: $13 \%, p=0.0002$ ) and self-reported (pain perception during daily activities: $-70 \%, p<0.0001$; at least: $-44 \%, p=0.04$; at worst: $-43 \%, p<0.0001$; functional outcome scores: $13 \%, p=0.0003$ ) functions improved after ten sessions of rehabilitation. The improved values were maintained after 4-weeks of detraining, but functional outcome scores showed an $8 \%$ further increase $(p=0.02)$. Regardless of electro-cryotherapy application prior to voluntary exercises at each session, quadriceps and self-reported function improved after ten sessions of rehabilitation for AKP. Improved functioning lasted throughout a 4-week detraining period.
\end{abstract}

Keywords: arthrogenous muscle inhibition; knee joint cooling; quadriceps function; patellofemoral pain syndrome; transcutaneous electrical nerve stimulation

\section{Introduction}

The primary concern during rehabilitative interventions for patients with anterior knee pain (AKP) is to reverse quadriceps weakness and activation deficit [1,2]. This quadriceps dysfunction is caused by alterations in motor output due to anomalous afferent sensory input from any source of AKP (e.g., combined or isolated pain [3], effusion [4], structural damage [5], or joint laxity [6]). Although this shut-down process is considered as a natural response that prevents further injury and provides time for healing, it often causes incomplete quadriceps activation. The persistent quadriceps dysfunction affects lower-extremity joint kinematics and kinetics [7], and may affect knee joint loading and increase risk of injury [8].

Among available interventions to reverse quadriceps inhibition, electrotherapy (e.g., transcutaneous electrical neuromuscular stimulation (TENS)) [9] and focal joint cooling [10] are two of the most accepted disinhibitory modalities. Furthermore, a series of rehabilitation interventions, consisting of TENS and/or knee joint cooling followed by voluntary exercises, have also been separately deployed in patients with anterior cruciate ligament (ACL) deficiency [11], ACL reconstruction [12], and knee osteoarthritis [13,14]. Although the above studies support the use of each modality treatment, there is no consensus that a combination of electro-cryotherapy in conjunction with strengthening exercises 
brings additional benefits, relative to the adoption of strengthening exercises alone. In 1985, Knight introduced an objective and optimal method of progression in the external load of voluntary exercise - the daily adjustable progressive resistance exercise (DAPRE) technique [15]. Since many reports [13,16-18] using this approach have demonstrated strength development in patients with AKP [17] and knee osteoarthritis $[13,16]$ the DAPRE technique would be suitable for use as a basis for the progression of strengthening exercises.

As such, the purpose of this study was to determine how ten-sessions of the DAPRE technique-based strengthening exercises, either in conjunction with or without electrocryotherapy applications, would improve quadriceps and self-reported function in patients with AKP. Secondarily, we were also interested in observing a detraining effect on both treatment conditions after ten-sessions of rehabilitation. We hypothesized that: (1) patients in both conditions would gain quadriceps function after the ten-session exercise rehabilitation program because the DAPRE technique is a notable method capable of improving quadriceps function from 4 to 6 weeks of rehabilitation [13,17], and (2) due to the effectiveness of therapeutic modalities [12,14], patients exposed to pre-exercise modalities (e.g., electro-cryotherapy) would show greater improvements in quadriceps and self-reported functions than would those performing exercises alone.

\section{Materials and Methods}

This study was a randomized clinical trial with two independent variables including condition (modality and exercise, and exercise alone) and time (pre- and post-rehabilitation, and detraining). Endpoints and outcome measures were (1) quadriceps function, as indicated by maximal voluntary isometric contraction (MVIC), central activation ratio (CAR), rate of torque development (RTD), and peak torque (PT) and (2) self-reported function, as indicated by visual analog scale (VAS) for pain perception and lower-extremity functional scale (LEFS). Sealed opaque envelopes were used for block-randomization allocation. The random allocation sequence was determined using the random function in a spreadsheet software (Excel 2013, Microsoft Inc., Redmond, WA, USA). The authors prepared for pre-filled envelopes and processed all data, and were blinded to participant enrolment, condition allocation, and supervision of the rehabilitation program.

\subsection{Subjects}

Thirty-nine patients with AKP initially volunteered; however, 4 were excluded and 5 dropped out (Figure 1 ). Thirty patients ( 19 males, 11 females, $21.2 \pm 1.0$ years, $171.8 \pm 2.8 \mathrm{~cm}$, $71.8 \pm 6.4 \mathrm{~kg}$, body mass index: $24.2 \pm 1.7$, time since pain: 46 months; Table 1) were completed the study. In this study, AKP was defined as feeling pain or discomfort during at least two of the following activities: ascending or descending stairs, sitting for longer than an hour, contraction of the quadriceps, or compressing the patella while sitting with the leg extended [18]. Additionally, eligible patients had to report having a pain perception greater than 2 out of $10 \mathrm{~cm}$ on the VAS during activities of daily living (ADL) [19]. Lastly, scores on the LEFS had to be less than 70 out of 80 points [20].

Exclusion criteria included athletic status, current pregnancy, or history of epilepsy, seizures, hearing impairments, or serious head injuries. Prior to participation, all patients read the study procedures and provided written informed consent, approved by the University's Institutional Review Board (approval \#: KHSIRB-18-002).

\subsection{Testing Procedures}

Patients visited the laboratory 13 times (ten times during rehabilitation; three times for measurements at pre- and post-rehabilitation, and detraining). On the first visit, patients completed paperwork (informed consent, health-history questionnaire, VAS, and LEFS), and were assessed body composition using a bioelectrical impedance device (InBody 770, Biospace Ltd., Seoul, Korea). After obtaining the end points of the pre-rehabilitation measurements (see Section 2.3. Endpoints), patients were block-randomized into one of two conditions (see Section 2.4. Treatment Conditions). Patients then visited the clinic and 
completed the ten rehabilitation sessions with a rest period of 48 hours between sessions (the 2nd through to 11th visit). Upon the completion of all the rehabilitation sessions, post-rehabilitation measurement values were recorded (the 12th visit: within 5 days from the last session day) using the same approach as that for the pre-rehabilitation measurements, followed by a 4-week detraining period. During this detraining period, patients were asked to neither participate in any physical activity nor undergo any therapeutic intervention. After a 4-week period of detraining, patients visited the laboratory again for the detraining measurements.

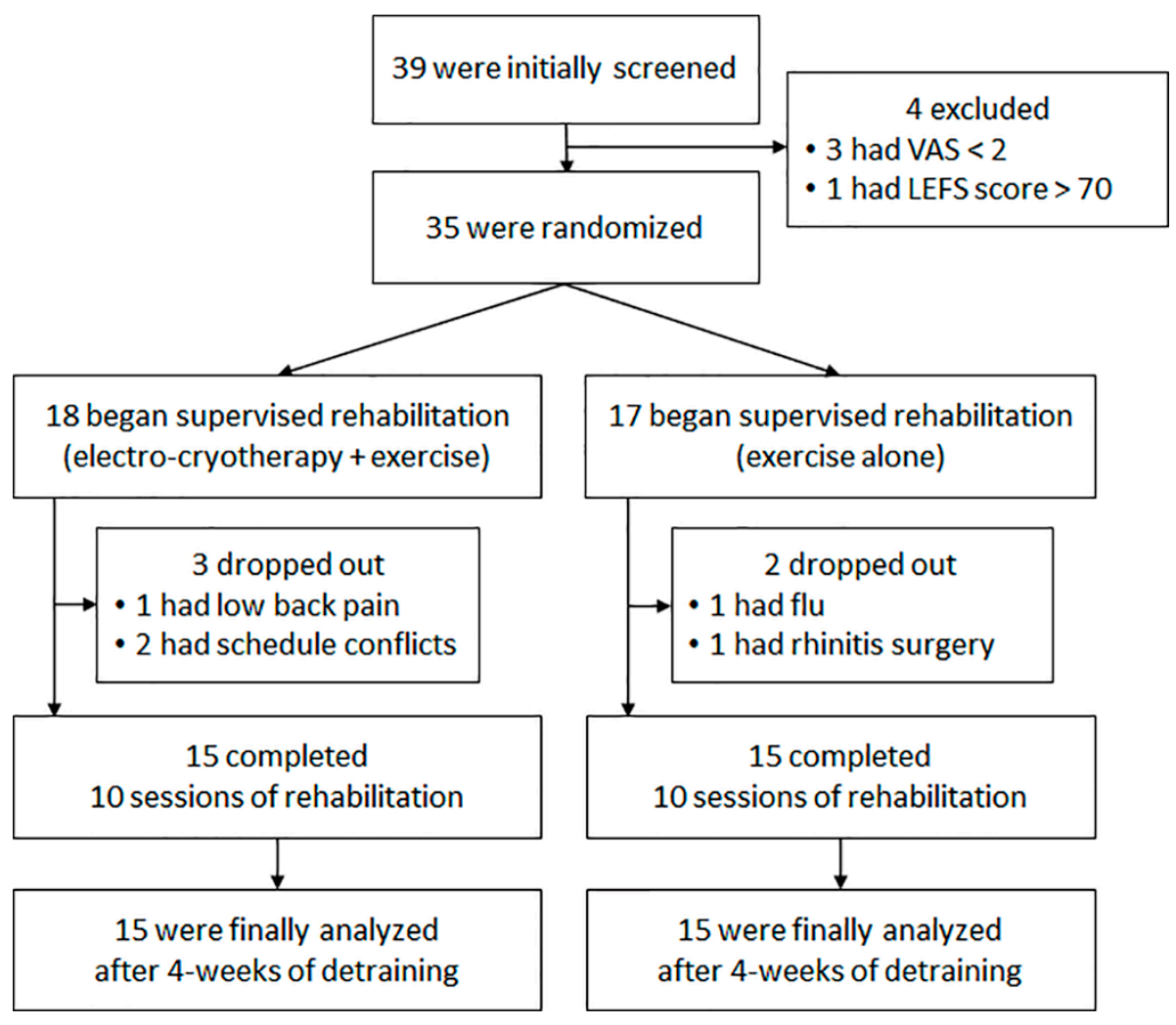

Figure 1. The progress of patients throughout the trial. LEFS: lower extremity functional scale; VAS: visual analog scale.

\subsection{Endpoints}

\subsubsection{Quadriceps Function}

With each patient sitting (knee fixed at $90^{\circ}$ and hip positioned at $85^{\circ}$ ) on an isokinetic dynamometer (Cybex 770, Cybex Inc., Medway, MA, USA), the anterior thigh was shaved and then cleaned with an alcohol swab for the electrode placements. Two electrodes $(7 \times 12.7 \mathrm{~cm}$, Dura-Stick II, Chattanooga, Hixson, TN, USA) were attached on the distal vastus medialis and the proximal vastus lateralis, respectively. Patients underwent a gradual warm-up of isometric contractions with submaximal electrical stimulus for the familiarization of the measurements [21]. Afterwards, 3 MVIC trials were conducted, with 90 -s rest periods in between. An electrical stimulus was manually delivered to the quadriceps through the electrodes when the MVIC torque reached a maximal plateau. The S48 Grass stimulator (Grass-Telefactor, West Warwick, RI, USA) was utilized to deliver electrical stimuli (100 pulses/s, $600 \mu$ s pulse duration, 10 train over $100 \mathrm{~ms}$ duration and $125 \mathrm{~V}$ with a peak output current of $450 \mathrm{~mA}$ ) directly onto the quadriceps to depolarize any remaining muscle fibers. CAR values were calculated by dividing torque measurements of the MVIC by the sum of the torque produced by the MVIC and the superimposed burst $(\mathrm{SIB})(\mathrm{CAR}=[\mathrm{MVIC} / \mathrm{MVIC}+\mathrm{SIB}$ torque] $\times 100)$ [22]. RTD was calculated by the slope of the torque-time curve ( $\Delta$ torque/ $\Delta$ time) between 0 to $100 \mathrm{~ms}$ after the onset of 
voluntary contraction ( $\geq 20 \mathrm{Nm}$ ) [23,24]. After a 90 -s rest from the last isometric contraction, patients then performed 30 repetitions of isokinetic contraction at $180^{\circ} / \mathrm{s}$ for quadriceps endurance [25]. The highest values of each repetition were averaged for the PT value. Each value of MVIC, RTD, and PT was normalized by lean body mass ( $\mathrm{Nm} / \mathrm{kg})$ [26].

Table 1. Descriptive statistics of the patients.

\begin{tabular}{|c|c|c|c|}
\hline $\mathrm{n} / \mathrm{mean} \pm 95 \% \mathrm{CI}$ & $\begin{array}{c}\text { Modality + Exercise } \\
\qquad(n=15)\end{array}$ & $\begin{array}{l}\text { Exercise Alone } \\
\quad(n=15)\end{array}$ & $p$-Value \\
\hline Age (year) & $20.6 \pm 1.2$ & $21.8 \pm 1.6$ & 0.25 \\
\hline $\operatorname{Sex}(M / F)$ & $9 / 6$ & $10 / 5$ & $\mathrm{~N} / \mathrm{A}$ \\
\hline Height (cm) & $170.7 \pm 4.6$ & $173.0 \pm 3.0$ & 0.42 \\
\hline Mass (kg) & $74.8 \pm 11.9$ & $68.7 \pm 4.6$ & 0.36 \\
\hline $\mathrm{BMI}\left(\mathrm{kg} / \mathrm{m}^{2}\right)$ & $25.4 \pm 6.3$ & $22.9 \pm 2.4$ & 0.17 \\
\hline LBM (kg) & $56.0 \pm 6.7$ & $53.7 \pm 4.5$ & 0.58 \\
\hline $\begin{array}{l}\text { Physical activity } \\
\text { (hours per week) }\end{array}$ & $3.3 \pm 1.1$ & $4.3 \pm 1.8$ & 0.41 \\
\hline Pain period (months) & $46.1 \pm 19.4$ & $45.0 \pm 16.8$ & 0.94 \\
\hline $\begin{array}{l}\text { Painful knee (L/R) } \\
\text { Injury type }\end{array}$ & $7 / 8$ & $8 / 7$ & $\mathrm{~N} / \mathrm{A}$ \\
\hline Atraumatic & 9 & 8 & $\mathrm{~N} / \mathrm{A}$ \\
\hline Traumatic & 6 & 7 & $\mathrm{~N} / \mathrm{A}$ \\
\hline History of knee surgery & 4 & 3 & $\mathrm{~N} / \mathrm{A}$ \\
\hline $\begin{array}{c}\text { Time since surgery (month) } \\
\text { Side-side ratio (\%) }\end{array}$ & $32.0 \pm 12.4$ & $56.0 \pm 21.5$ & $\mathrm{~N} / \mathrm{A}$ \\
\hline MVIC & $92.2 \pm 10.9$ & $95.1 \pm 12.5$ & 0.69 \\
\hline$C A R$ & $98.9 \pm 8.5$ & $96.6 \pm 8.4$ & 0.62 \\
\hline RTD & $87.0 \pm 10.1$ & $101.2 \pm 12.8$ & 0.26 \\
\hline$P T$ & $93.3 \pm 6.9$ & $97.2 \pm 7.6$ & 0.37 \\
\hline
\end{tabular}

ADL: activities of daily living; BMI: body mass index; CAR: central activation ratio; CI: confidence intervals F: female; L: left; LBM: lean body mass; M: male; MVIC: maximal voluntary isometric contraction; N/A: not applicable; PT: peak torque; R: right.

\subsubsection{Self-Reported Function}

A $10 \mathrm{~cm}$ VAS [27] was used to quantify pain perception. Patients were asked to mark the level of pain during ADL, and at least- and worst-pain perception. The LEFS [20] score was obtained for the individual level of lower-extremity function. These were gathered prior to the assessment of quadriceps function.

\subsection{Treatment Conditions}

Patients in both conditions underwent a ten-session rehabilitation program with a 2-day rest period included between sessions.

\subsubsection{Modality + Exercise}

Patients received a 30-min simultaneous application of TENS and knee joint cooling on the involved leg. TENS device (TENS 3000 unit, Koalaty Products Inc., Tampa, FL, USA) and 4 self-adhesive square electrodes $(5 \times 5 \mathrm{~cm}$, Protens-tens electrodes 4848 , Bio-Protech Inc., Gangwon-do, Korea; Figure 2A) were used to deliver a sensory level of asymmetric biphasic current (pulse duration: $150 \mu$ s; pulse rate: $150 \mathrm{~Hz}$ [12,14]. The intensity was set at the highest amplitude that could be reached without any muscle contraction or subjective uncomfortable sensations noted. For cryotherapy, 2 plastic bags $(20 \times 40 \mathrm{~cm})$ of crushed ice $(1 \mathrm{~L})$ were attached on the anterior and the posterior aspects of the knee joint, and secured using plastic wrap (Figure 2B) [28]. Afterwards, patients performed voluntary exercises 
for $30 \mathrm{~min}$. The program contained warming-up, stretching, strengthening, and balancing exercises (Table 2). For the strengthening exercises, the exercise intensity (i.e., external load) was determined by the DAPRE technique [15].

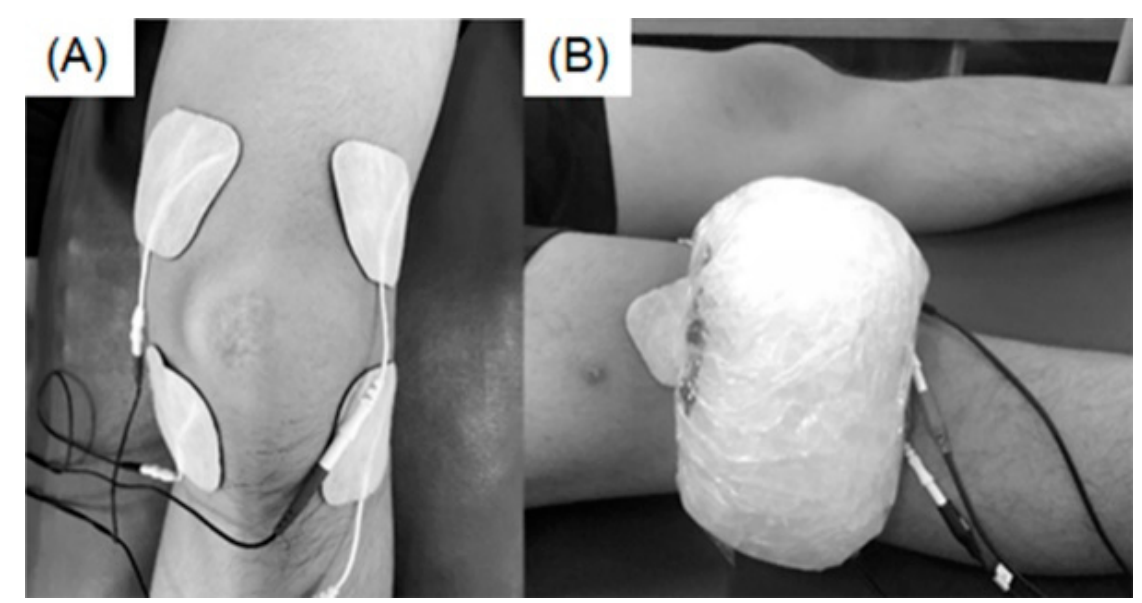

Figure 2. Electro-cryotherapy: electrode attachments were set for 2 channels of TENS (A) and 2 ice bags were secured by plastic wrap $(\mathbf{B})$.

Table 2. DAPRE technique-based exercise program.

\begin{tabular}{ccc}
\hline Exercise & Volume or Duration & Intensity or Progression \\
\hline Jogging & 5 -min & $\begin{array}{c}\text { Treadmill speed } \\
\text { at } 6.0 \text { to } 8.5 \mathrm{~km} / \mathrm{h}\end{array}$ \\
\hline Stretching * & A 30-s hold $\times 2$ sets & $\begin{array}{c}\text { Until mild discomfort is felt } \\
\text { at the end range of motion }\end{array}$ \\
\hline SLRs ${ }^{* *}$ & 8 reps $\times 3$ sets & Leg weight \\
\hline $\begin{array}{c}\text { Knee extensions }{ }^{* *} ; \\
\text { Lunges }{ }^{* *} \text {; Squats }+\end{array}$ & 4 sets & $\begin{array}{c}\text { Determined by } \\
\text { the DAPRE technique }\end{array}$ \\
\hline Balance & A 30-second balance \\
$\times 3$ sets & $\begin{array}{c}\text { Static (eyes-open or closed; on a } \\
\text { balance pad) and dynamic balance }\end{array}$ \\
\hline
\end{tabular}

DAPRE: daily adjustable progressive resistive exercise; SLR: straight leg raises. ${ }^{*}$ hip extension/flexion, knee extension/flexion, ankle dorsiflexion. ${ }^{* *}$ performed in the $1 \mathrm{st}, 3 \mathrm{rd}, 5$ th, 7 th, and 9 th sessions. + performed in the 2nd, 4th, 6th, 8th, and 10th sessions.

\subsubsection{Exercise Alone}

The same exercise program, described above, was performed without receiving electrocryotherapy.

\subsection{Statistical Analysis}

Our sample size was determined using an expected mean difference in the quadriceps activation of 0.11 with a standard deviation (SD) of 0.14 , which yielded an effect size (ES) of $0.80[18,29]$. We used an alpha of 0.05 and a beta of 0.2 . These calculations estimated that a group of 14 patients in each condition was necessary. Considering the dropout rate during the study period (a total of 7.5 weeks), we initially recruited 35 patients (Figure 1).

Mean, SD, and 95\% confidence intervals were calculated from each dependent measurement (quadriceps and self-reported functions) at each time point.

To test condition effects over time, two-way mixed model analysis of variances (random variable: subjects; fixed variables: condition and time) and Tukey-Kramer pairwise comparisons for post hoc tests were performed. To determine practical significance between condition and time, Cohen's d effect size [30] and their 95\% confidence intervals (ESCI) were also calculated.

SAS 9.4 (SAS Institute Inc., Cary, NC, USA) was used for all tests $(p<0.05)$. 


\section{Results}

\subsection{Quadriceps Function}

There was no condition effect over time (condition $\times$ time) in MVIC $\left(\mathrm{F}_{2,56}=0.21\right.$, $p=0.82), \operatorname{CAR}\left(\mathrm{F}_{2,56}=0.29, p=0.75\right), \operatorname{RTD}\left(\mathrm{F}_{2,56}=0.51, p=0.60\right)$, and PT $\left(\mathrm{F}_{2,56}=0.08\right.$, $p=0.92)$, suggesting that the addition of pre-exercise modality did not affect change quadriceps function (Table 3 and Figure 3).

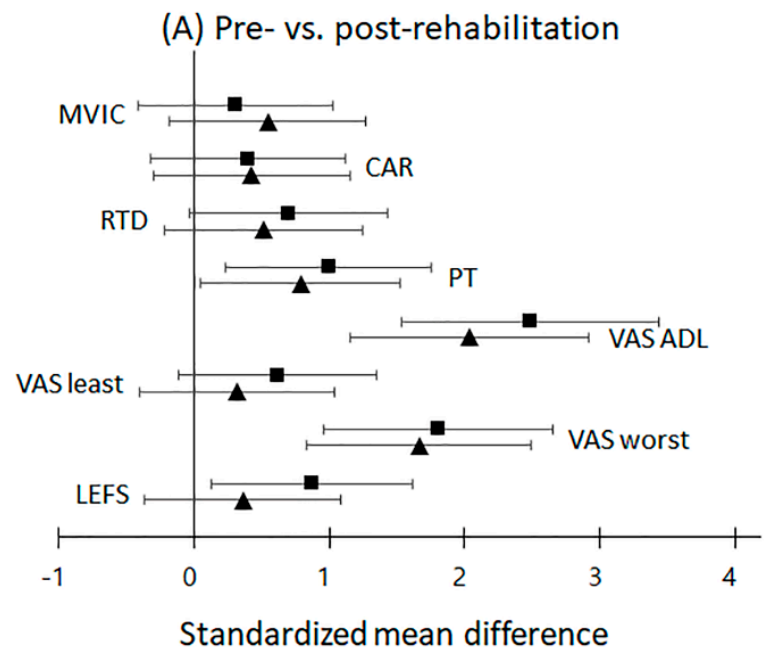

(B) Pre-rehabilitation vs. detraining

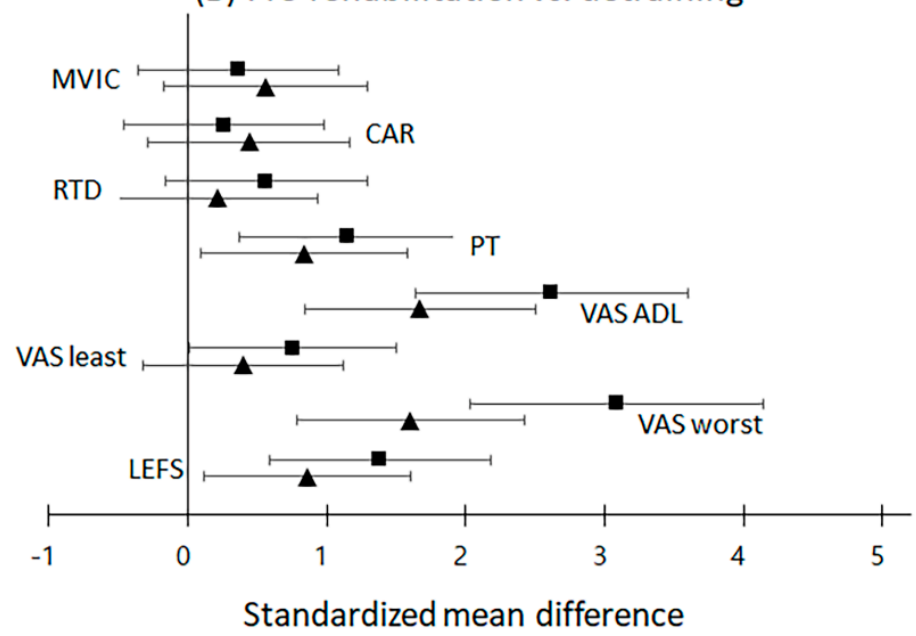

Figure 3. Forest plots of the outcome measures. Squares (modality + exercise condition) and triangles (exercise alone) with $95 \%$ confidence intervals indicate effect size estimates of mean difference between pre- and post-rehabilitation (A) and between pre-rehabilitation and detraining (B). All effect sizes and confidence intervals are positive (on the right side of the vertical zero line), indicating that either treatment condition was beneficial; confidence intervals of each outcome measure (e.g., MVIC) overlap, indicating the difference between treatment conditions were not statistically different. ADL: activities of daily livings; CAR: central activation ratio; LEFS: lower-extremity functional scales; MVIC: maximal voluntary isometric contraction; PT: peak torque; VAS: visual analog scale.

There was no condition effect for MVIC $\left(\mathrm{F}_{1,56}=0.02, p=0.90\right)$, CAR $\left(\mathrm{F}_{1,56}=0.32\right.$, $p=0.58)$, $\operatorname{RTD}\left(\mathrm{F}_{1,56}=0.26, p=0.62\right)$, and PT $\left(\mathrm{F}_{1,56}=0.01, p=0.99\right)$.

Regardless of the disinhibitory modality application (time effect), quadriceps MVIC $\left(\mathrm{F}_{2,56}=3.96, p=0.03\right), \operatorname{RTD}\left(\mathrm{F}_{2,56}=5.38, p=0.007\right)$, and PT $\left(\mathrm{F}_{2,56}=14.43, p<0.0001\right)$ were changed. Specifically, the values in $\operatorname{RTD}(20 \%, p=0.006, \mathrm{ES}=0.62, \mathrm{ESCI}=0.10$ to 1.14$)$ 
and PT $(13 \%, p=0.0002, \mathrm{ES}=0.90, \mathrm{ESCI}=0.36$ to 1.43$)$ increased at post-rehabilitation and were maintained after the 4 -week detraining period (RTD: $p=0.57$; PT: $p=0.76$ ). Separately, quadriceps MVIC increased after 4 weeks of detraining $(12 \%, p=0.04, \mathrm{ES}=0.47$, $\mathrm{ESCI}=-0.05$ to 0.98$)$. There was no time effect on $\mathrm{CAR}\left(\mathrm{F}_{2,56}=2.56, p=0.09\right)$.

Table 3. Changes in quadriceps function.

\begin{tabular}{ccccc}
\hline Mean $\mathbf{\pm}$ 95\% CI & $\begin{array}{c}\text { Modality } \\
\text { + Exercise } \\
(\boldsymbol{n}=\mathbf{1 5})\end{array}$ & $\begin{array}{c}\text { Exercise } \\
\text { Alone } \\
(\boldsymbol{n}=\mathbf{1 5})\end{array}$ & $\begin{array}{c}\text { Combined } \\
(\boldsymbol{n}=\mathbf{3 0})\end{array}$ \\
\hline $\mathrm{MVIC}$ & Pre-rehabilitation & $2.6 \pm 0.3$ & $2.6 \pm 0.3$ & $2.6 \pm 0.2$ \\
$(\mathrm{Nm} / \mathrm{kg})$ & Post-rehabilitation & $2.9 \pm 0.4$ & $3.0 \pm 0.4$ & $2.9 \pm 0.2$ \\
& Detraining & $2.9 \pm 0.4$ & $3.0 \pm 0.4$ & $2.9 \pm 0.2^{*}$ \\
\hline $\mathrm{CAR}$ & Pre-rehabilitation & $81.0 \pm 5.1$ & $81.2 \pm 7.6$ & $81.1 \pm 3.2$ \\
$(\%)$ & Post-rehabilitation & $85.1 \pm 5.2$ & $86.5 \pm 4.8$ & $85.8 \pm 2.5$ \\
& Detraining & $83.6 \pm 4.8$ & $87.2 \pm 6.1$ & $85.4 \pm 2.7$ \\
\hline \multirow{2}{*}{$\mathrm{RTD}(\mathrm{Nm} / \mathrm{kg} / \mathrm{s})$} & Pre-rehabilitation & $10.6 \pm 1.7$ & $10.8 \pm 1.5$ & $10.7 \pm 0.8$ \\
& Post-rehabilitation & $13.2 \pm 2.1$ & $12.4 \pm 1.7$ & $12.8 \pm 0.9 *$ \\
& Detraining & $12.7 \pm 2.0$ & $11.6 \pm 2.2$ & $12.2 \pm 1.0$ \\
\hline \multirow{2}{*}{$\mathrm{PT}$} & Pre-rehabilitation & $1.5 \pm 0.1$ & $1.5 \pm 0.1$ & $1.5 \pm 0.1$ \\
$(\mathrm{Nm} / \mathrm{kg})$ & Post-rehabilitation & $1.7 \pm 0.1$ & $1.7 \pm 0.1$ & $1.7 \pm 0.1^{* *}$ \\
& Detraining & $1.7 \pm 0.1$ & $1.7 \pm 0.2$ & $1.7 \pm 0.1^{* *}$ \\
\hline
\end{tabular}

CAR: central activation ratio; CI: confidence intervals; MVIC: maximal voluntary isometric contraction; PT: peak torque; RTD: rate of torque development. ${ }^{*}$ Different from the pre-rehabilitation measurement $(p<0.05)$. ${ }_{* *}$ Different from the pre-rehabilitation measurement $(p<0.01)$.

\subsection{Self-Reported Function}

There was no condition effect over time (condition $\times$ time) in VAS (ADL: $F_{2,56}=0.66$, $p=0.52$; least: $\mathrm{F}_{2,56}=0.37, p=0.69$; worst: $\left.\mathrm{F}_{2,56}=0.85, p=0.43\right)$ and LEFS $\left(\mathrm{F}_{2,56}=2.27\right.$, $p=0.11$ ) scores (Table 4 and Figure 3). There was no condition effect for VAS (ADL: $\mathrm{F}_{1,56}=0.02, p=0.89$; least: $\mathrm{F}_{1,56}=0.28, p=0.60$; worst: $\left.\mathrm{F}_{1,56}=0.18, p=0.68\right)$, and LEFS $\left(\mathrm{F}_{1,56}=0.70, p=0.41\right)$.

Table 4. Changes in self-reported function.

\begin{tabular}{|c|c|c|c|c|}
\hline \multicolumn{2}{|c|}{ Mean $\pm 95 \%$ CI } & \multirow{2}{*}{$\begin{array}{c}\begin{array}{c}\text { Modality } \\
+ \text { Exercise } \\
(\boldsymbol{n}=\mathbf{1 5})\end{array} \\
4.3 \pm 0.8\end{array}$} & \multirow{2}{*}{$\begin{array}{c}\begin{array}{c}\text { Exercise } \\
\text { Alone } \\
(\boldsymbol{n}=\mathbf{1 5})\end{array} \\
4.0 \pm 0.9\end{array}$} & \multirow{2}{*}{$\begin{array}{c}\begin{array}{c}\text { Combined } \\
(n=30)\end{array} \\
4.2 \pm 0.6\end{array}$} \\
\hline & Pre-rehabilitation & & & \\
\hline VAS during ADL & Post-rehabilitation & $1.3 \pm 0.4$ & $1.2 \pm 0.3$ & $1.3 \pm 0.3 *$ \\
\hline & Detraining & $1.1 \pm 0.4$ & $1.4 \pm 0.7$ & $1.2 \pm 0.4^{*}$ \\
\hline \multirow{3}{*}{ VAS at least $(\mathrm{cm})$} & Pre-rehabilitation & $1.2 \pm 0.6$ & $0.9 \pm 0.7$ & $1.0 \pm 0.4$ \\
\hline & Post-rehabilitation & $0.6 \pm 0.4$ & $0.5 \pm 0.3$ & $0.6 \pm 0.2 * *$ \\
\hline & Detraining & $0.5 \pm 0.4$ & $0.5 \pm 0.3$ & $0.5 \pm 0.2 * *$ \\
\hline \multirow{3}{*}{$\begin{array}{l}\text { VAS at worst } \\
(\mathrm{cm})\end{array}$} & Pre-rehabilitation & $7.3 \pm 0.7$ & $6.6 \pm 0.9$ & $7.0 \pm 0.6$ \\
\hline & Post-rehabilitation & $4.1 \pm 1.1$ & $3.9 \pm 0.8$ & $4.0 \pm 0.7 *$ \\
\hline & Detraining & $3.2 \pm 0.7$ & $3.5 \pm 1.1$ & $3.3 \pm 0.6^{*}$ \\
\hline \multirow{3}{*}{$\begin{array}{c}\text { LEFS } \\
\text { (scores) }\end{array}$} & Pre-rehabilitation & $49.3 \pm 5.5$ & $56.3 \pm 5.1$ & $52.8 \pm 3.9$ \\
\hline & Post-rehabilitation & $59.1 \pm 5.8$ & $60.6 \pm 6.8$ & $59.8 \pm 4.4^{* *}$ \\
\hline & Detraining & $64.2 \pm 5.4$ & $64.5 \pm 4.5$ & $64.4 \pm 3.5^{*, \dagger}$ \\
\hline
\end{tabular}

ADL: activities of daily livings; CI: confidence intervals; LEFS: lower-extremity functional scale; VAS: visual analog scale. ${ }^{*}$ Different from the pre-rehabilitation measurement $(p<0.0001) .{ }^{* *}$ Different from the pre-rehabilitation measurement $(p<0.05)$. + Different from the post-rehabilitation measurement $(p<0.05)$.

Regardless of the use of disinhibitory modalities (time effect), pain perception during $\operatorname{ADL}\left(\mathrm{F}_{2,56}=67.18, p<0.0001\right)$, and at least $\left(\mathrm{F}_{2,56}=5.28, p=0.008\right)$ and worst $\left(\mathrm{F}_{2,56}=53.24\right.$, $p<0.0001$ ) were changed. Specifically, pain perception reduced at post-rehabilitation (ADL: 
$-70 \%, p<0.0001, \mathrm{ES}=2.28, \mathrm{ESCI}=1.63$ to 2.93 ; least: $-44 \%, p=0.04, \mathrm{ES}=0.46, \mathrm{ESCI}=0.05$ to 0.98 ; worst: $-43 \%, p<0.0001$, ES $=1.75$, ESCI $=1.15$ to 2.34$)$, and the decreased values were maintained after 4 weeks of detraining period (ADL: $p=0.98$; least: $p=0.83$; worst: $p=0.23)$.

Regardless of modality applications (time effect: $\mathrm{F}_{2,56}=24.22, p<0.0001$ ), the LEFS score increased post-rehabilitation $(13 \%, p=0.0003, \mathrm{ES}=0.60, \mathrm{ESCI}=0.08$ to 1.12$)$, and increased again after the detraining period (post-rehabilitation versus 4 weeks postrehabilitation: $8 \%, p=0.02, \mathrm{ES}=0.41, \mathrm{ESCI}=-0.10$ to 0.92 ).

\section{Discussion}

This study aimed to examine whether the application of simultaneous TENS and focal joint cooling prior to strengthening exercises in AKP patients produces greater improvements in quadriceps and self-reported functions over ten sessions of rehabilitation and 4 weeks of rest thereafter. We observed that the endpoints (quadriceps and self-reported functions) improved in both treatment conditions (Tables 3 and 4). The levels of improvement were not different between the conditions, indicating that there was no therapeutic advantage in receiving an additional $30 \mathrm{~min}$ of disinhibitory modality. Improved training effects on quadriceps (RTD and PT) and self-reported functions (pain during ADL, and at least- and worst-pain perception) persisted for 4 weeks of detraining. Interestingly, however, the first increase in quadriceps MVIC and the second improvement in LEFS were seen 4 weeks after rehabilitation (Tables 3 and 4).

An immediate increase in quadriceps function by the use of TENS [4,9] or knee joint cooling $[10,28]$ is well-documented. Sensory inputs from either TENS or knee joint cooling are thought to inhibit Ib inhibitory interneuron and facilitate Ia excitatory interneurons [28]. Additionally, TENS also activates descending mechanism, mediated at supraspinal level, which assists in the inhibition of Ib interneurons [4]. Knee joint cooling is thought to reduce the recruitment threshold of the motor unit and nerve conduction velocity [31]. Therefore, we expected that patients who received electro-cryotherapy would be able to exert greater external load when performing resistance exercises. Variations in treatment parameters, knee pathologies, and muscle contraction mode may explain why we did not observe such disinhibitory effects. First, a large volume of TENS treatments (at least 8 hours per day for 4 weeks) was applied for the study reported beneficial effect on the use of TENS in patients with knee osteoarthritis [14]. A shorter TENS application (60 min for 20 sessions) did not show additional improvements in the same pathological population while our treatment (30 min for ten sessions) was insufficient to elicit what we expected. Second, a therapeutic advantage (greater quadriceps improvement) was also observed in patients with ACL reconstruction [12]. Osteoarthritis and ACL reconstructions are more severe knee pathologies where the potential for improvement could be larger, relative to in patients with chronic AKP. Lastly, a recent study observed that an application of 20 min electrocryotherapy did not restore altered running mechanics due to experimentally induced knee pain [32]. Since previous quadriceps disinhibition was observed in a static supine position [4] or with isometric contraction [9,10,28], our isotonic exercise (also requiring co-contractions with other muscles) may have suppressed a disinhibitory effect.

Pain perception ( 4.2 to $1.3 \mathrm{~cm}$ in VAS, ES = 2.28) and lower-extremity functional outcomes (53 to 60 points in LEFS, ES $=0.60$ ) were also improved regardless of modality usage. Even if there was little or no disinhibitory effect, greater improvements in selfreported functions were expected in patients receiving electro-cryotherapy due to the known analgesic effect of TENS and focal joint cooling. Additionally, numbing the painful area by electro-cryotherapy application could have possibly allowed for pain-free exercises or increased the exercise tolerance. These results are, in fact, consistent with previously conducted similar training studies $[11,12,14,33]$ where functional outcome measures were not different among the treatment groups. While TENS and/or knee joint cooling resulted in an immediate reduction in pain perception by experimentally induced AKP $[9,32,34]$, the limitations on the cumulative analgesic effect of repetitive use of TENS [35] and 
cryotherapy [36] have also been suggested. Hence, long-term benefits on the use of therapeutic modalities, as the addition to strengthening exercises, in patients with knee joint pathologies remain unclear. In this regard, our results also suggest that patients with chronic AKP may achieve therapeutic effects by performing ten sessions over 3.5 weeks of the DAPRE technique-based strengthening exercises alone. Our patients could have adapted to performing exercise training by repetitive muscle contractions over ten sessions, which possibly increased joint stability and movement efficiency, resulting in gradual pain reduction [35]. Since RTD is the ability for rapid muscular force exertion [37], an improvement in quadriceps RTD $(20 \%, \mathrm{ES}=0.62)$ might lead to increased knee joint power in the sagittal plane [38]. Additionally, 95\% confidence intervals for quadriceps PT $(13 \%, E S=0.90)$ do not contain zeros, suggesting that an improvement in quadriceps endurance is clinically meaningful. Therefore, observations of increased quadriceps power and endurance at post-rehabilitation also support the idea that the conduct of resistance exercises with functional movements (particularly squats and lunges) could have made daily activities easier. This could have been associated with significant reductions in pain during ADL and at the worst pain level, which could explain why lower-extremity functional outcomes showed a further improvement after the 4-week detraining period.

Although between-group differences were determined in LEFS score, the associated $95 \%$ confidence intervals do not contain zero in the condition of modality + exercise (Figure 3), an advantage of electro-cryotherapy in promoting functional improvements may exist. Looking at the LEFS scores, those of patients who received electro-cryotherapy increased by almost 10 points (ES $=0.87$ ), whereas those of patients who performed exercise only increased 4 points (ES $=0.36$ ). A LEFS score of 9 points is known as the minimal clinically important difference [20] where we still recommend applying electrocryotherapy in every session during rehabilitation exercise for AKP patients. Interestingly, the effect sizes calculated in the condition of modality + exercise are consistently larger than those in exercise alone after rehabilitation and even grew larger in a comparison of pre-rehabilitation and detraining ( $\mathrm{cm}$ in VAS during ADL: 2.6 versus 1.7; at worst: 3.1 versus 1.6; LEFS: 1.4 versus 0.9 ). As previously reported, concerning the effect of TENS and cryotherapy in reducing residual pain after therapeutic exercises [35], patients received electro-cryotherapy in our study may have been likely to go home in better physical (or psychological) condition during and after the rehabilitation program.

The application of study outcomes to the pathological population may be a limitation because $20 \%(7 / 35)$ of our patients had a history of knee surgeries (ACL reconstruction: $n=2$, posterior cruciate ligament reconstruction: $n=1$, meniscal surgery: $n=2$, ACL reconstruction and meniscal surgery: $n=2$ ). However, quadriceps (MVIC: 2.3 versus $2.7 \mathrm{Nm} / \mathrm{kg}$; CAR: 0.8 versus 0.8 ) and self-reported functions (VAS during ADL: 3.6 versus $4.1 \mathrm{~cm}$; LEFS: 50 versus 53 points) at the beginning of rehabilitation in patients with surgical history were not different from those who did not have surgeries. Additionally, those patients with surgical history were somewhat evenly allocated ( 3 and 4 in each treatment condition), which could have also minimized the heterogeneity of patient characteristics. The average rehabilitation period of our patients was 24 days. We assume that further improvements (e.g., muscle hypertrophy) beyond what we observed could be expected if patients would participate in additional exercise training. Ten sessions, however, was the maximum number that we asked our patients to attend due to rehabilitation adherence and detraining.

\section{Conclusions}

Patients with chronic AKP who received 30 minutes of pre-exercise disinhibitory modalities (simultaneous application of TENS and knee joint cooling) followed by $30 \mathrm{~min}$ of DAPRE technique-based strengthening exercises for ten sessions of rehabilitation to achieve similar improvements in quadriceps and self-reported functions when compared with those who received $30 \mathrm{~min}$ of strengthening exercises alone. Improved quadriceps and self-reported function were maintained after 4 weeks of detraining. Although there 
were no statistical between-condition differences, the between-time ES in self-reported functioning was consistently larger (and continued growing further after detraining) in the treatment condition that received electro-cryotherapy.

Author Contributions: Conceptualization, Y.R. and J.P.; methodology, Y.R. and J.P.; formal analysis, Y.R. and J.P.; investigation, J.P.; resources, J.P.; data curation, Y.R.; writing-original draft preparation, Y.R. and J.P.; writing-review and editing, Y.R. and J.P.; visualization, Y.R. and J.P.; supervision, J.P.; funding acquisition, J.P. Both authors have read and agreed to the published version of the manuscript.

Funding: This work was supported by the Ministry of Education of the Republic of Korea and the National Research Foundation of Korea (NRF-2017S1A5A8022854).

Institutional Review Board Statement: The study was conducted according to the guidelines of the Declaration of Helsinki and approved by the University's Institutional Review Board (KHSIRB-18-002, Kyung Hee University).

Informed Consent Statement: Informed consent was obtained from all patients involved in the study.

Data Availability Statement: Data are not publicly available due to privacy.

Acknowledgments: We thank Minsub Oh, Joohee Lee, Sungwan Kim, Hyunji Doo, and Sanghyun Song for their assistance in data collection and reduction.

Conflicts of Interest: The authors declare no conflict of interest.

\section{References}

1. Ingram, T.G.; Roddick, J.M.; Byrne, J.M. Is gamma loop dysfunction related to bilateral inhibition in anterior knee pain? Muscle Nerve 2016, 53, 280-286. [CrossRef] [PubMed]

2. Guney, H.; Yuksel, I.; Kaya, D.; Doral, M.N. The relationship between quadriceps strength and joint position sense, functional outcome and painful activities in patellofemoral pain syndrome. Knee. Surg. Sport. Traumatol. Arthrosc. 2016, 24, $2966-2972$. [CrossRef] [PubMed]

3. Park, J.; Hopkins, J.T. Induced anterior knee pain immediately reduces involuntary and voluntary quadriceps activation. Clin. J. Sport Med. 2013, 23, 19-24. [CrossRef]

4. Hopkins, J.T.; Ingersoll, C.D.; Edwards, J.; Klootwyk, T.E. Cryotherapy and transcutaneous electric neuromuscular stimulation decrease arthrogenic muscle inhibition of the vastus medialis after knee joint effusion. J. Athl. Train. 2002, 37, 25-31. [PubMed]

5. Garstang, S.V.; Stitik, T.P. Osteoarthritis: Epidemiology, risk factors, and pathophysiology. Am. J. Phys. Med. Rehabil. 2006, 85, S2-S11. [CrossRef]

6. Hart, J.M.; Pietrosimone, B.; Hertel, J.; Ingersoll, C.D. Quadriceps activation following knee injuries: A systematic review. J. Athl. Train. 2010, 45, 87-97. [CrossRef] [PubMed]

7. Paoloni, M.; Mangone, M.; Fratocchi, G.; Murgia, M.; Saraceni, V.M.; Santilli, V. Kinematic and kinetic features of normal level walking in patellofemoral pain syndrome: More than a sagittal plane alteration. J. Biomech. 2010, 43, 1794-1798. [CrossRef]

8. Weiss, K.; Whatman, C. Biomechanics associated with patellofemoral pain and ACL injuries in sports. Sports Med. 2015, 45, 1325-1337. [CrossRef] [PubMed]

9. Son, S.; Kim, H.; Seeley, M.; Feland, J.; Hopkins, J. Effects of transcutaneous electrical nerve stimulation on quadriceps function in individuals with experimental knee pain. Scand. J. Med. Sci. Sports 2016, 26, 1080-1090. [CrossRef]

10. Rice, D.A.; McNair, P.J.; Dalbeth, N. Effects of cryotherapy on arthrogenic muscle inhibition using an experimental model of knee swelling. Arthritis Rheum. 2009, 61, 78-83. [CrossRef]

11. Hart, J.M.; Kuenze, C.M.; Pietrosimone, B.G.; Ingersoll, C.D. Quadriceps function in anterior cruciate ligament-deficient knees exercising with transcutaneous electrical nerve stimulation and cryotherapy: A randomized controlled study. Clin. Rehabil. 2012, 26, 974-981. [CrossRef]

12. Hart, J.M.; Kuenze, C.M.; Diduch, D.R.; Ingersoll, C.D. Quadriceps muscle function after rehabilitation with cryotherapy in patients with anterior cruciate ligament reconstruction. J. Athl. Train. 2014, 49, 733-739. [CrossRef] [PubMed]

13. Pietrosimone, B.G.; Saliba, S.A.; Hart, J.M.; Hertel, J.; Kerrigan, D.C.; Ingersoll, C.D. Effects of disinhibitory transcutaneous electrical nerve stimulation and therapeutic exercise on sagittal plane peak knee kinematics and kinetics in people with knee osteoarthritis during gait: A randomized controlled trial. Clin. Rehabil. 2010, 24, 1091-1101. [CrossRef] [PubMed]

14. Pietrosimone, B.G.; Saliba, S.A.; Hart, J.M.; Hertel, J.; Kerrigan, D.C.; Ingersoll, C.D. Effects of transcutaneous electrical nerve stimulation and therapeutic exercise on quadriceps activation in people with tibiofemoral osteoarthritis. J. Orthop. Sports Phys. Ther. 2011, 41, 4-12. [CrossRef] [PubMed]

15. Knight, K.L. Quadriceps strengthening with the DAPRE technique: Case studies with neurological implications. Med. Sci. Sports Exerc. 1985, 17, 646-650. [CrossRef] [PubMed] 
16. Pietrosimone, B.G.; Saliba, S.A.; Hart, J.M.; Hertel, J.; Ingersoll, C.D. Contralateral effects of disinhibitory TENS on quadriceps function in people with knee osteoarthritis following unilateral treatment. N. Am. J. Sports Phys. Ther. 2010, 5, 111. [PubMed]

17. Herrington, L.; Al-Sherhi, A. A controlled trial of weight-bearing versus non-weight-bearing exercises for patellofemoral pain. J. Orthop. Sports Phys. Ther. 2007, 37, 155-160. [CrossRef]

18. Park, J.; Grindstaff, T.L.; Hart, J.M.; Hertel, J.N.; Ingersoll, C.D. Knee-extension exercise's lack of immediate effect on maximal voluntary quadriceps torque and activation in individuals with anterior knee pain. J. Sport. Rehabil. 2012, 21, 119-126. [CrossRef]

19. Tyler, T.F.; Nicholas, S.J.; Mullaney, M.J.; McHugh, M.P. The role of hip muscle function in the treatment of patellofemoral pain syndrome. Am. J. Sports Med. 2006, 34, 630-636. [CrossRef]

20. Alcock, G.; Werstine, M.; Robbins, S.; Stratford, P. Longitudinal changes in the lower extremity functional scale after anterior cruciate ligament reconstructive surgery. Clin. J. Sport Med. 2012, 22, 234-239. [CrossRef]

21. Grindstaff, T.L.; Hertel, J.; Beazell, J.R.; Magrum, E.M.; Ingersoll, C.D. Effects of lumbopelvic joint manipulation on quadriceps activation and strength in healthy individuals. Man. Ther. 2009, 14, 415-420. [CrossRef] [PubMed]

22. Kent-Braun, J.A.; Le Blanc, R. Quantification of central activation failure during maximal voluntary contractions in humans. Muscle Nerve 1996, 19, 861-869. [CrossRef]

23. Kline, P.W.; Morgan, K.D.; Johnson, D.L.; Ireland, M.L.; Noehren, B. Impaired quadriceps rate of torque development and knee mechanics after anterior cruciate ligament reconstruction with patellar tendon autograft. Am. J. Sports Med. 2015, 43, 2553-2558. [CrossRef] [PubMed]

24. Andersen, L.L.; Aagaard, P. Influence of maximal muscle strength and intrinsic muscle contractile properties on contractile rate of force development. Eur. J. Appl. Physiol. 2006, 96, 46-52. [CrossRef]

25. Pincivero, D.M.; Gandaio, C.B.; Ito, Y. Gender-specific knee extensor torque, flexor torque, and muscle fatigue responses during maximal effort contractions. Eur. J. Appl. Physiol. 2003, 89, 134-141. [CrossRef] [PubMed]

26. Van Den Ham, E.C.H.; Kooman, J.P.; Schols, A.M.; Nieman, F.H.M.; Does, J.D.; Franssen, F.M.E.; Akkermans, M.A.; Janssen, P.P.; van Hooff, J.P. Similarities in skeletal muscle strength and exercise capacity between renal transplant and hemodialysis patients. Am. J. Transplant. 2005, 5, 1957-1965. [CrossRef]

27. Bijur, P.E.; Silver, W.; Gallagher, E.J. Reliability of the visual analog scale for measurement of acute pain. Acad. Emerg. Med. 2001, 8, 1153-1157. [CrossRef] [PubMed]

28. Pietrosimone, B.G.; Hart, J.M.; Saliba, S.A.; Hertel, J.; Ingersoll, C.D. Immediate effects of transcutaneous electrical nerve stimulation and focal knee joint cooling on quadriceps activation. Med. Sci. Sports Exerc. 2009, 41, 1175-1181. [CrossRef]

29. Pamukoff, D.N.; Pietrosimone, B.G.; Ryan, E.D.; Lee, D.R.; Blackburn, J.T. Quadriceps function and hamstrings co-activation after anterior cruciate ligament reconstruction. J. Athl. Train. 2017, 52, 422-428. [CrossRef] [PubMed]

30. Cohen, J. Quantitative methods in psychology: A power primer. Psychol. Bull. 1992, 112, 1155-1159. [CrossRef]

31. Enwemeka, C.S.; Allen, C.; Avila, P.; Bina, J.; Konrade, J.; Munns, S. Soft tissue thermodynamics before, during, and after cold pack therapy. Med. Sci. Sports Exerc. 2002, 34, 45-50. [CrossRef]

32. Kwon, S.; Bruening, D.A.; Morrin, S.J.; Kunz, D.M.; Hopkins, J.T.; Seeley, M.K. Simultaneous ice and transcutaneous electrical nerve stimulation decrease anterior knee pain during running but do not affect running kinematics or associated muscle inhibition. Clin. Biomech. 2020, 72, 1-7. [CrossRef]

33. Cheing, G.L.; Hui-Chan, C.W. Would the addition of TENS to exercise training produce better physical performance outcomes in people with knee osteoarthritis than either intervention alone? Clin. Rehabil. 2004, 18, 487-497. [CrossRef]

34. Park, J.; Hopkins, J.T. Immediate effects of acupuncture and cryotherapy on quadriceps motoneuron pool excitability: Randomised trial using anterior knee infusion model. Acupunct. Med. 2012, 30, 195-202. [CrossRef] [PubMed]

35. Cheing, G.L.; Hui-Chan, C.W.; Chan, K. Does four weeks of TENS and/or isometric exercise produce cumulative reduction of osteoarthritic knee pain? Clin. Rehabil. 2002, 16, 749-760. [CrossRef] [PubMed]

36. Hubbard, T.J.; Denegar, C.R. Does cryotherapy improve outcomes with soft tissue injury? J. Athl. Train. 2004, 39, 278-279. [PubMed]

37. Aagaard, P.; Simonsen, E.B.; Andersen, J.L.; Magnusson, P.S.; Dyhre-Poulsen, P. Increase rate of force development and neural drive of human skeletal muscle following resistance training. J. Appl. Physiol. 2002, 93, 1318-1326. [CrossRef]

38. Winters, J.D.; Rudolph, K.S. Quadriceps rate of force development affects gait and function in people with knee osteoarthritis. Eur. J. Appl. Physiol. 2014, 114, 273-284. [CrossRef] [PubMed] 